\title{
Uma análise discursiva da prova de redação do ENEM: o sujeito surdo na rede de sentidos
}

\author{
A discursive analysis from ENEM essay test: the deaf subject in the network of \\ meanings \\ Edson Santos de LIMA* \\ Universidade Federal de São Carlos (UFSCar) \\ Maria Eliza Freitas do NASCIMENTO** \\ Universidade do Estado do Rio Grande do Norte (UERN)
}

\begin{abstract}
RESUMO: A inclusão social de sujeitos com deficiência no ambiente escolar, nas universidades e em diversas esferas sociais nunca foi tão discutida como na atualidade. Tanto como forma de buscar condições mais igualitárias quanto no combate às discriminações ainda existentes, ambos vieses são favoráveis às sociedades que se pretendem igualitárias e democráticas. Desse modo, embasados nos pressupostos da Análise do Discurso de vertente francesa (doravante $\mathrm{AD}$ ), iremos analisar os enunciados da prova de redação do ENEM do ano de 2017, destacando as relações de poder-saber que produzem efeitos de sentidos na relação com a memória discursiva de exclusão social, a fim de compreendermos como se dá a construção de vontades de verdade sobre os sujeitos Surdos. Na análise, os efeitos de sentido são construídos relacionados às estratégias de governamentalidade, com respaldo do biopoder, marcando formas de discursividades que normatizam práticas sobre a educação de sujeitos surdos.
\end{abstract}

PALAVRAS-CHAVE: Discurso. Efeitos de sentido. Sujeito Surdo.

ABSTRACT: The social inclusion of subjects with disabilities in the school environment, in universities and in various social spheres has never been more discussed than it is today. As a way of seeking more egalitarian conditions, and another one in combating discrimination that still exists, both perspectives are favorable to societies that claim to be egalitarian and democratic. Thus, based on the assumptions of French Discourse Analysis (hereinafter AD), we will analyze the discourses from ENEM essay test of 2017, highlighting the power-knowledge relations that produce effects of meanings in its relations with memory discourse of social exclusion, in order to understand how the construction of truths about Deaf subjects occured. In the analysis, the effects of meaning are constructed related to governmentality strategies, supported by biopower, marking forms of discourses that standardize practices about the education of deaf subjects.

KEYWORDS: Discourse. Effects of meanings. Deaf Subject.

\footnotetext{
* Doutorando em Linguística pelo Programa de Pós-Graduação em Linguística da Universidade Federal de São Carlos/SP. E-mail: edsonsantosln@hotmail.com.

** Professora Adjunta da Universidade do Estado do Rio Grande do Norte - UERN. E-mail: elizamfn@hotmail.com.
} 


\section{Introdução}

A proposta de redação do Exame Nacional do Ensino Médio (ENEM) promove, por um lado, uma prática inclusiva através de incisivos procedimentos de controle e disciplina da população e por outro reforça lugares de opressão social de alguns grupos em específico. Isso porque nos referimos ao enunciado: "Desafios para a formaçãoeducacional de surdos no Brasil", repercutido nacionalmente como tema da redação no ano de 2017, o qual pôs em visibilidade dizeres sobre os sujeitos Surdos e os desafios que estes ainda enfrentam como forma de marcar um lugar social, por meio de ferramentas de poder e saber, os quais dão legitimidade à inclusão destes, na atualidade, nas instituições públicas e privadas de ensino no Brasil. Tais sujeitos, dos quais trataremos aqui, possuem um grau profundo de deficiência auditiva e fazem uso da Língua Brasileira de Sinais (LIBRAS) para se comunicar.

Ao buscar a análise do discurso da inclusão dos sujeitos Surdos, importa-nos perceber o que é dito e suas relações com outros campos discursivos, pois os enunciados possuem "sempre margens povoadas por outros enunciados" (FOUCAULT, 2009, p. 110). Todo e qualquer discurso é produto de uma formulação controlada e selecionada, como já nos disse Foucault (2013), cabe-nos perceber as interdições e os controles postos em circulação, a fim de compreendermos essas estratégias postas em uso no cenário nacional, por dar vazão às discussões sobre o grupo das pessoas com deficiência e seus obstáculos diários. Tais sujeitos foram por longos tempos alvos de exclusão dos ambientes de ensino, e só nos dias de hoje é que vemos uma incursão dos aparatos políticos e econômicos para bem controlar e governar a população, fazendo jus a uma visibilidade proposital e emancipadora de ordem governamental.

Por efetivas práticas discursivas, toma-se, na presente investigação, o discurso enquanto acontecimento tecido na história, que resgata memórias discursivas de discriminação e por tudo o que é dito sobre os sujeitos Surdos. Constata-se, então, a possibilidade de se fazer uma investigação de como o sujeito Surdo é discursivizado na rede de discursos da prova de redação do ENEM/2017 através do exercício da função enunciativa sob o respaldo do método arqueogenealógico proposto por Michel Foucault. Segundo Fernandes (2012), há pesquisas que contemplam tal método, abrangendo, além da fase arqueológica, a genealógica e a última fase, a ética e estética da existência. Aqui 
nos deteremos nas duas primeiras, pois nos propomos, primeiramente, abordar o discurso e a proposta da prova de redação como acontecimento discursivo, os quais oportunizam o trabalho de uma atualidade sobre o sujeito Surdo e a comunidade surda como práticas legitimadas. Em seguida, iremos analisar os enunciados da prova de redação do ENEM, destacando as relações de poder construídas em rede, as quais produzem efeitos de sentidos na relação com a memória discursiva de exclusão social, para compreendermos como se dá a construção de vontades de verdade sobre os sujeitos Surdos.

Desse modo, embasados nos pressupostos da Análise do Discurso de vertente francesa (doravante $\mathrm{AD}$ ) e na análise da materialidade discursiva, enfocaremos os dizeres que abordam o tema da educação inclusiva, os quais constroem efeitos de sentido relacionados às estratégias de governamentalidade, com respaldo do biopoder. A seguir abordaremos algumas reflexões sobre as relações de poder.

\section{O corpo em (dis)curso e as relações de poder}

As discussões em torno do poder perpassam alguns dos escritos de Michel Foucault, pois tal conceito é inseparável das verdades e dos saberes de cada época. Torna-se importante o destaque do exercício sinuoso, desde um poder soberano marcado no século XVI, um poder disciplinar entre os séculos XVII e XVIII até o exercício de estratégias de governamentalidade, de forma mais marcada a partir do século XIX, que se pulveriza na atualidade e produz saberes sobre a vida, regulando-a.

O poder funciona nas ações do cotidiano e não se filia a uma instituição, pois está em toda parte e se efetiva em discurso. Nessa perspectiva, não se consegue identificar o centro do poder, ele ocupa as malhas sociais nas diversas instâncias reguladas por saberes, através de micropoderes. Desse modo, é nas práticas do cotidiano que o poder consolida ações em sociedade, no jogo de forças e condutas, disseminado por diferentes relações que envolvem os sujeitos em épocas distintas.

Nesse sentido, entender o poder em uma ótica que vai do poder soberano ao biopoder é compreender as articulações disciplinares e normativas que buscam controlar o corpo. Por isso, tais discussões ganharam auge com a docilização dos corpos desde o 
século XVI em específicas condições de produção, as quais redirecionam as relações de poder-saber na marcação de seu tratamento no tempo e espaço.

Nessa perspectiva, as análises do poder são afetadas pelas condições de emergência em que os discursos são instituídos e, por essa característica de exterioridade, perpetuam-se novas produções sobre o corpo com deficiência. Assim sendo, há distanciamento das instituições que promovem o poder disciplinar, conferido por regras e sistemas, ainda, tradicionais de ensino, todavia considerando os fatores sociais e pedagógicos que influenciam no aprendizado desses sujeitos que sofrem com as exclusões.

Na legitimidade do poder não mais sobre o corpo-espécie e agora, mais ainda, sobre o corpo-população, modificam-se os discursos amparados por novas relações de poder-saber sobre o corpo com deficiência presentes nos discursos, sobretudo, nos que tratam da educação inclusiva. Sob as lentes do projeto genealógico, os regimes de saberes conduzem micropoderes no interior das práticas discursivas e não discursivas.

Com o advento de outras relações de poder e saber sobre os indivíduos, questões econômicas, com ênfase no mercado de trabalho, são reestruturadas e a docilização dos corpos para as práticas trabalhistas se tornaram importantes. O que marca a passagem do poder soberano ao disciplinar é que "a economia das ilegalidades se reestruturou com o desenvolvimento da sociedade capitalista" (FOUCAULT, 2014, p. 86). Nesse sentido, as punições tornaram-se ainda menos explícitas, com intuito de controlar as condutas sociais.

O poder disciplinar ganhou destaque entre os séculos XVIII e XIX e o exercício do poder instituiu-se mais nos corpos do que no território. Nesse período, o poder não mais se concentrava no Estado e em suas formas de repressão, mas sobre o corpo do indivíduo, sendo por essa direção que "a disciplina fabrica assim corpos submissos e exercitados" (FOUCAULT, 2014, p. 135). No período do poder disciplinar, as técnicas do poder se fragmentaram com a função de tornar os corpos dóceis, mais produtivos por meio do controle e de um bom adestramento.

Portanto, ao situarmos as indagações de Foucault sobre as relações de poder em sua fase genealógica, ele observa as relações discursivas que imprimem efeitos nas práticas não discursivas e na promoção de novas condutas sociais. É com o surgimento de novas formas de gerir os indivíduos e as ações da vida cotidiana que surge uma outra 
face do biopoder, por meio do governo, não mais do corpo individual e sim da população, a biopolítica, que entra para legitimar e conduzir a vida social. A arte de governar aparece na sociedade ocidental desde o século XVIII, mas é a partir do século XIX e através do exercício do poder sobre a vida das pessoas que o modo sutil de disciplinar e gerir a população ganha consistência e destaque.

Com isso, os procedimentos de segurança e a ação da biopolítica entram no rol das ferramentas para governar melhor a população. À vista disso, as práticas cotidianas são observadas, desde a taxa de natalidade, mortalidade, saúde pública, habitação, entre outras, para minimizar as perdas, os índices de mortes, regulando-se a vida e o corpo. Por assim dizer, o filósofo se refere à governamentalidade, definida como sendo o “conjunto constituído pelas instituições, procedimentos, análises e reflexões, cálculos e táticas que permitem exercer esta forma bastante específica e complexa de poder, que tem por alvo a população" (FOUCAULT, 2015, p. 429).

O instrumento do governo será a população, no intuito de melhor governar a todos, para um bem-estar coletivo. Diminuir os índices de morte, incentivar as boas condutas para prevenir doenças ou maus hábitos são instrumentos que buscam promover a saúde coletiva de todos e por todos no exercício das estratégias da governamentalidade. Consequentemente, pode-se observar as estratégias da educação inclusiva que repercutem na sociedade como mecanismos de educabilidade do corpo com deficiência para que esses sejam normalizados e possam ser produtivos na sociedade. O poder soberano agia para segregar o corpo com deficiência e, diferentemente, na atualidade o corpo é alvo da ordem da inclusão social.

Nesse sentido, as miras do poder são automaticamente delimitadas, instituídas e condicionadas por um conjunto de procedimentos. O corpo é tido como objeto e alvo do biopoder, na sociedade que preza pelo controle minucioso da vida, do corpo social. Com isso, no cotidiano, é vivenciada a arte de governar em um exercício sobre a população por efeitos de um espaço múltiplo, variado e diverso. A produção de saberes faz funcionar novas multiplicidades, buscando a normalização dos sujeitos.

Pelo regime do que é dito e das implicações no jogo de forças, é sustentada a produção de um determinado saber na sociedade. O discurso da educação inclusiva do corpo com deficiência determina específicas estratégias de inscrição desses pela ótica do discurso normalizador, por meio das estratégias da governamentalidade, que visam à 
segurança, ao bem-estar e ao apoio à perspectiva inclusiva. Conforme Foucault (2005, p. 302), a sociedade normalizadora "é uma sociedade em que se cruzam, conforme uma articulação ortogonal, a norma da disciplina e a norma da regulamentação".

Um dos principais elementos que movem as estratégias de gerência da população é o desejo de que, por meio dele, a população se torne penetrável às estratégias do poder (FOUCAULT, 2015). À vista disso, o acontecimento discursivo da proposta de redação do ENEM/2017, nosso objeto de análise, constitui-se, enquanto produção discursiva, como uma dessas formas de governo da população, ao penetrar no desejo dos sujeitos de ingressar em práticas não discursivas, por exemplo, a da entrada na universidade através do exame.

\section{Discursos e efeitos de sentidos: analisando os enunciados da prova de redação do ENEM/2017}

Para melhor compreender a irrupção do acontecimento discursivo da prova de redação, visando compreender as regras de formação do objeto discursivizado, vale salientar que o ENEM foi criado pelo Instituto Nacional de Estudos e Pesquisas Educacionais (INEP) em 1998, para ser aplicado anualmente aos alunos concluintes do Ensino Médio e aos egressos desse nível de ensino. O exame é importante para os estudantes e permite, exclusivamente, o acesso ao ensino superior em instituições privadas e públicas em todo o Brasil. Ele objetiva "avaliar o desempenho do aluno ao término da escolaridade básica, para aferir o desenvolvimento de competências fundamentais ao exercício pleno da cidadania" (BRASIL, 2002, p. 5).

Dito isso, as práticas sociais que inscrevem os sujeitos Surdos na sociedade fazem funcionar estratégias de normalização, na ordem do discurso da educação inclusiva. Com efeito, a prova do ENEM é uma produção discursiva que promove estratégias de controle e de disciplina para todas as pessoas que se submetem a participar do exame em busca de ingressar no ensino superior. Também há mecanismos que cerceiam esse acesso, caso o aluno não alcance a nota exigida, já que, nessa produção discursiva, ocorrem mecanismos normatizadores, oportunizados por estratégias de governamentalidade que regulamentam as práticas sociais dos sujeitos que se submetem ao exame. 
Com essas reflexões, a prova de redação do ENEM/2017 é considerada uma produção que enfatiza uma série de discursividades sobre o sujeito Surdo. Assim, em face à visão da arqueologia do saber no que tange à formação discursiva, a prova se configura como uma superfície de emergência para esse objeto, a qual possibilita uma leitura na contemplação do funcionamento discursivo e do exercício da função enunciativa.

Discutindo a prática discursiva e não discursiva, no interior dos discursos que envolvem o saber pedagógico, o exame do ENEM se constitui como um dispositivo que envolve questões objetivas das áreas da Natureza, Humanas, Matemática, Linguagens e códigos e suas tecnologias, as quais apresentam alternativas para o candidato escolher entre essas a opção correta. O método de avaliação dessas provas é com base na Teoria de Resposta ao Item (TRI), abordagem que não contabiliza apenas o número total de acertos no teste. A avaliação da prova de redação segue um método de avaliação diferente, em que a pontuação pode ser de 0 (zero) a 1.000 (mil).

Passemos à análise dos enunciados que envolvem a produção discursiva da prova de redação do ENEM, que materializam vontades de verdades sobre a temática, seja para disciplinar as condutas, estigmatizar ideias ou para manter uma visibilidade proposital e oportuna aos que sofrem com o desrespeito e a discriminação por conta de suas diferenças. Os efeitos de sentido construídos nos enunciados marcam o conjunto de habilidades cognitivas e textuais que normatizam e disciplinam a escrita dos candidatos e, ao serem atendidas, os sujeitos se marcam discursivamente, respeitando as diversidades e os direitos humanos, bem como a norma culta da língua portuguesa.

Figura 1: Prova de redação do ENEM/2017.

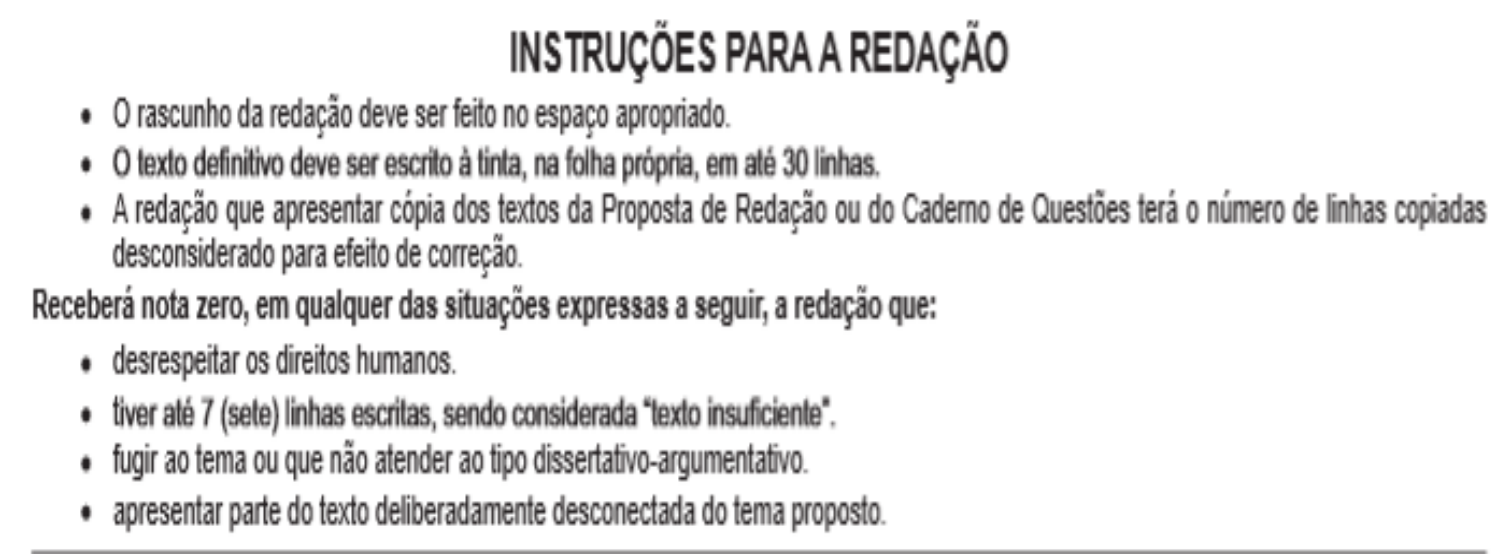

Revista Moara, n. 58, jan-jul 2021 ISSN: 0104-0944 


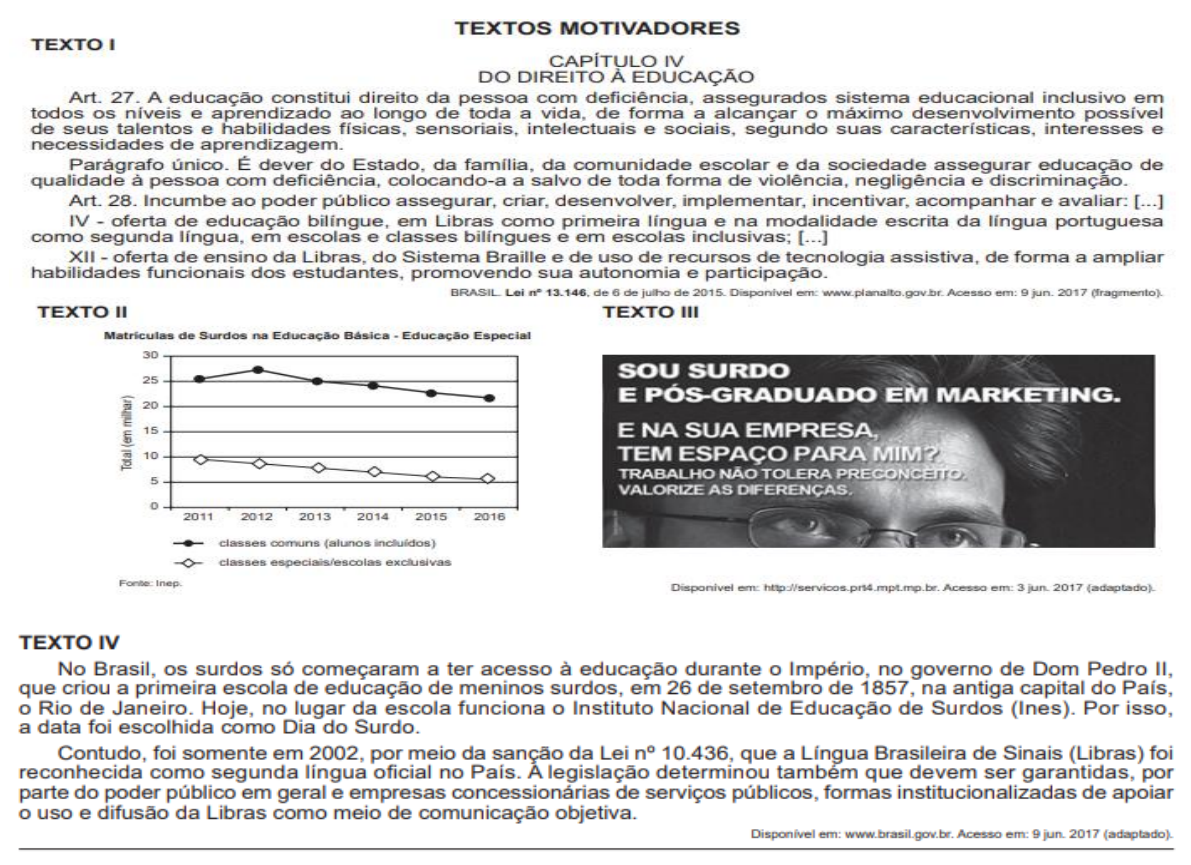

\section{PROPOSTA DE REDAÇÃO}

A partir da leitura dos textos motivadores e com base nos conhecimentos construídos ao longo de sua formaç̃o, redija texto dissertativo-argumentativo em modalidade escrita formal da língua portuguesa sobre 0 tema "Desafios para a formaçăo educacional de surdos no Brasil", apresentando proposta de intervençăo que respeite os direitos humanos. Selecione, organize e relacione, de forma coerente e coesa, argumentos e fatos para defesa de seu ponto de vista.

Fonte: www.inep.com.br_caderno2_prova_amarela

Os discursos marcam as verdades historicamente constituídas. $\mathrm{Na}$ análise da prova de redação ocorre a marcação de efeitos de sujeição nas orientações para a escrita da redação. O enunciado intitulado "Instruções para a redação" (INEP, 2017, p. 19) destina-se a disciplinar e a conduzir a escrita do texto pelos candidatos no espaço apropriado. Com o uso da palavra "instruções", é reforçado o sentido de orientar os candidatos e informar sobre as advertências que causam nota zero na redação.

Esse enunciado discursivo das instruções sinaliza o sentido para a produção de corpos dóceis, com o exercício do poder disciplinar. O enunciado verbal "Instruções para a Redação" é apresentado em letras maiúsculas e em negrito, o que produz um disciplinamento aos sujeitos na ordem do discurso instrucional que oportuniza guiar as condutas dos participantes com a presença de informações curtas e objetivas. Tal rede de enunciados, que constituem as instruções mobiliza estratégias discursivas de orientação, normatizando o que deve ser feito e o que deve ser escrito. Na presença do enunciado "Receberá nota zero, em qualquer das situações expressas a seguir, a redação 
que" (INEP, 2017, p. 19), promove-se um efeito de sentido de advertência sobre os casos em que o aluno receberá nota zero, caso não siga as ordens.

O uso da palavra "zero" reitera o efeito de sentido de alerta para as ocorrências inapropriadas. Nesse caso, o sujeito da enunciação é legitimado pelo Instituto Nacional de Pesquisas Educacionais (INEP), que marca a presença do poder disciplinar que dita e orienta as regras e governa a vida desse grupo da população que se submete ao exame, já que "sabe-se bem que não se tem o direito de dizer tudo, que não se pode falar de tudo em qualquer circunstância" (FOUCAULT, 2013, p. 9). O efeito de sentido de orientação nos enunciados é potencializado por haver um "padrão" de correção a ser seguido e de uma escrita, ou seja, a norma de uma escrita e estrutura ideal que deve ser atingida para que os sujeitos consigam uma boa pontuação.

Continuando as análises, a prova de redação do ENEM/2017 marca discursivamente a produção de saberes que normatizam a educação inclusiva por meio do ensino de LIBRAS, destacando os efeitos de governamentalidade e a operação de vontades de verdade que incidem no espaço da formação educacional. Assim, constituem-se os enunciados considerados "textos motivadores", os quais servem para subsidiar o desenvolvimento dos candidatos na redação. Esses enunciados configuram discursos que emergem de outros lugares, oportunizando a imersão do enunciado em uma série, na irrupção do arquivo das dizibilidades sobre o sujeito Surdo.

No uso da palavra "motivadores", retoma-se um discurso de que o sujeito candidato necessita de incentivo para aclarar suas ideias a respeito do tema da redação. Assim, a presença de outros discursos emerge nos "textos motivadores", se enquadrando como possibilidades de uso, auxiliando para que os candidatos consigam alcançar uma boa pontuação na prova de redação. Diante disso, pode-se dizer que esses enunciados agem por estratégias de controle; ao se dirigirem a um interlocutor, guiandolhe para desenvolver uma proposta de intervenção relevante sobre o tema, o que por outro lado congrega formas de governar a deficiência, através do saber jurídico com as leis e decretos, com vista a amenizar a história de exclusão.

$\mathrm{Na}$ análise discursiva, os quatro enunciados destacados como "textos motivadores" são provenientes de diferentes gêneros: enunciados verbais, gráfico e imagem. Torna-se oportuno retomar, entre as considerações postas por Foucault (2009) a respeito dos enunciados, que esses não são frases, proposições ou atos de falas, são 
constituídos no interior da função enunciativa, que precisa de uma existência material, além de outras características.

Sendo assim, os enunciados dos "textos motivadores" são lidos como discursos que constroem vontades de verdade, atravessados por relações de poder-saber. Desse modo, por um trajeto de discursividades, tornam-se discursivizadas no enunciado do "Texto I", as práticas da educação, de educabilidade dos sujeitos Surdos e de normatização da LIBRAS presentes no discurso jurídico, como sendo uma estratégia de governamentalidade disposta na Lei de Inclusão da Pessoa com Deficiência - Lei $\mathrm{n}^{\circ}$ 13.146, de 6 de Julho de 2015, como é apresentado:

\footnotetext{
Art. 27. A educação constitui direito da pessoa com deficiência, assegurado sistema educacional inclusivo em todos os níveis e aprendizado ao longo de toda a vida, de forma a alcançar o máximo desenvolvimento possível de seus talentos e habilidades físicas, sensoriais, intelectuais e sociais, segundo suas características, interesses e necessidades de aprendizagem.

Parágrafo único. É dever do Estado, da família, da comunidade escolar e da sociedade assegurar educação de qualidade à pessoa com deficiência, colocando-a a salvo de toda forma de violência, negligência e discriminação. Art. 28. Incumbe ao poder público assegurar, criar, desenvolver, implementar, incentivar, acompanhar e avaliar: [...]

IV - oferta de educação bilíngue, em Libras como primeira língua e na modalidade escrita da língua portuguesa como segunda língua, em escolas e classes bilíngues e em escolas inclusivas; [...]

XII - oferta de ensino da Libras, do Sistema Braille e de uso de recursos de tecnologia assistiva, de forma a ampliar habilidades funcionais dos estudantes, promovendo sua autonomia e participação (INEP, 2017, p. 19).
}

Desse modo, o discurso do texto motivador I configura-se como um dispositivo de segurança pelas relações estabelecidas na ordem do discurso da educação inclusiva. Percebe-se o agenciamento de estratégias que objetivam a normalização do corpo com deficiência. Mecanismos esses que buscam legitimar o direito à educação através de um poder sobre a vida. Como uma ferramenta de biopolítica, articulada à inclusão do sujeito com deficiência no espaço escolar, o sentido de se alcançar a máxima produtividade desses alunos é o elemento a ser superado para que eles desenvolvam seus talentos e habilidades em todos os níveis de ensino.

A vigilância é um instrumento de controle que também se constrói na presença de determinadas relações de poder-saber presentes nesse discurso. Para tanto, no intuito de docilizar o corpo com deficiência, a disciplina atua como forma de vigiar e controlar 
os comportamentos. O poder estatal busca atingir o máximo de desempenhos e habilidades individuais de cada aluno com deficiência no espaço escolar e social.

Assim, observa-se, ao analisar o enunciado "É dever do Estado, da família, da comunidade escolar e da sociedade assegurar educação de qualidade à pessoa com deficiência, colocando-a a salvo de toda forma de violência, negligência e discriminação" (INEP, 2017, p. 19), que o sentido se constrói diante da marcação de sujeitos institucionais legitimados a assegurarem o bom desempenho, a educabilidade dos alunos, vigiando-os, para que a educação ocorra em todos os ambientes e que, assim, não haja o contato de influências desagradáveis e inapropriadas que possam retirá-los da norma.

Os sentidos também são construídos diante da historicidade, percebida com o uso da palavra "discriminação", há um resgate da memória discursiva, em que as pessoas com deficiência são discriminadas por não fazerem parte da regra social legitimada por específicas relações de poder. É importante considerar, no discurso em análise, que as estratégias de governar o corpo com deficiência sinalizam que "foi no biológico, no somático, no corporal que, antes de tudo, investiu a sociedade capitalista. O corpo é uma realidade biopolítica" (FOUCAULT, 2015, p. 144).

Os saberes médicos e pedagógicos discursivizam o corpo com deficiência na superação das dificuldades para que consiga se desenvolver no ambiente educacional de forma satisfatória, estando assim inserido na sociedade e no mercado de trabalho. Esse efeito de sentido é reforçado com o enunciado do Art. 27, no seguinte trecho: “[...] de forma a alcançar o máximo desenvolvimento possível de seus talentos e habilidades físicas, sensoriais, intelectuais e sociais, segundo suas características, interesses e necessidades de aprendizagem" (INEP, 2017, p. 19). Na ordem do discurso da inclusão social, a inscrição do corpo com deficiência como um ser produtivo é criado por mecanismos ajustáveis e técnicas ao exercício do biopoder na prática educativa. A educação surge, aqui, como uma estratégia do poder que vai evitar a exclusão dos sujeitos com deficiência. Logo, os sentidos são construídos pela articulação entre os enunciados e outros que os precedem.

Com base nessa reflexão, destacam-se as práticas discursivas efetivadas, ao resgatar uma historicidade, as quais colocaram à margem o corpo com deficiência e que, agora, busca inclui-lo. A segregação do corpo com deficiência no paradigma da 
exclusão inscreve a subjetividade de um sujeito incapaz de se desenvolver de acordo com o padrão normativo da sociedade. É perceptível que, com as mudanças nas condições e nos regimes de verdade sobre o corpo com deficiência, entram em cena, na ordem da biopolítica, as estratégias de gerir, conduzir e governar os corpos.

Nesse sentido, destaca-se o sujeito Surdo como o corpo que recebe essa atenção na inscrição dos efeitos da educabilidade através da governamentalidade. Na presença de um domínio de memória, discursivizam-se no interdiscurso as práticas que segregaram o corpo com deficiência. Todavia, o paradigma da exclusão perdurou por um longo tempo, através do discurso jurídico é possível percebermos a construção de um efeito de sentido de salvação, de amparo para com estes sujeitos, destacado no enunciado "[...] colocando-a a salvo de toda forma de violência, negligência e discriminação" (INEP, 2017, p. 19). Essa questão possibilita pensar as relações de poder em decorrência das vontades de verdade de diferentes épocas.

Ainda analisando o enunciado "Texto I", da prova de redação do ENEM, as estratégias do biopoder ocorrem pela incidência de elementos históricos que promovem a dispersão dos enunciados em rede, o que se efetiva no social. É possível ler nos capítulos IV e XII do Art. 28, uma técnica do governo para promover o uso da LIBRAS com vistas a assegurar o protagonismo dos sujeitos Surdos no Brasil, uma vez que a oferta da educação bilíngue é uma estratégia de governamentalidade que busca normatizá-los de acordo com a norma da comunidade ouvinte que usa a Língua Portuguesa.

Esse efeito de sentido que busca ressaltar as diferenças, constrói-se no discurso jurídico no nunciado "IV - oferta de educação bilíngue, em Libras como primeira língua e na modalidade escrita da língua portuguesa como segunda língua, em escolas e classes bilíngues e em escolas inclusivas" (INEP, 2017, p. 19), no qual se percebem as relações de poder e de saber na Lei de Inclusão da Pessoa com Deficiência. Esse discurso é posto em funcionamento para que se possa normalizar e incluir os sujeitos Surdos no espaço escolar brasileiro através do uso da LIBRAS.

As estratégias de governamentalidade são agenciadas pela oferta da lei de LIBRAS nas escolas brasileiras, fazendo funcionar, através do discurso jurídico, uma efetivação do desenvolvimento pessoal e profissional dos sujeitos, o que é reforçado no seguinte enunciado "XII - oferta de ensino da Libras, do Sistema Braille e de uso de 
recursos de tecnologia assistiva, de forma a ampliar habilidades funcionais dos estudantes, promovendo sua autonomia e participação" (INEP, 2017, p. 19).

O uso das palavras "autonomia" e "participação" reitera o efeito de sentido de inclusão nas diferentes esferas sociais. Então, é assim que, nas práticas educativas o poder de normalização é agenciado por meio dos saberes pedagógicos que promovem a comunicação dos sujeitos Surdos com os ouvintes e vice-versa por meio da LIBRAS. Nota-se, também, no enunciado acima exposto, que são destacados os recursos tecnológicos como elementos que farão com que o sujeito Surdo possa assumir sua posição de protagonista de sua aprendizagem, por meio do uso dessas ferramentas de inclusão social.

O enunciado do "Texto II" é representado por um gráfico intitulado "Matrículas de Surdos na Educação Básica - Educação especial”, possui a seguinte legenda “classes comuns (alunos incluídos)" e "classes especiais/escolas exclusivas". Esse enunciado mostra a proporção do total de alunos entre o período de 2011 a 2016. Os números possibilitam quantificar determinadas ações, no controle do corpo e governo da população, sendo uma estratégia de governamentalidade.

Para tanto, uma singularidade nessa materialidade discursiva é a da produção de diferentes efeitos de sentido no resgate histórico e no uso dos termos "classes comuns" e "classes especiais". Ao interpretar o enunciado, percebe-se um aumento em 2012 do total de alunos com deficiência, não apenas dos sujeitos Surdos matriculados nas classes comuns; no entanto, após esse ano, não houve alterações significativas permanecendo o declínio no total de alunos matriculados em ambos os espaços.

Esse discurso é possível de ser recuperado ao colocarmos em diálogos os outros dizeres que se efetivaram como acontecimento discursivo referente ao dado estatístico no gráfico em detrimento das mudanças nas práticas sociais. O crescimento do número de alunos matriculados adveio da estratégia de governamentalidade, através da Lei $\mathrm{n}^{\circ}$ 12.764, de 27 de dezembro de 2012, especificamente em relação ao seguinte enunciado “Art. $7^{\circ} \mathrm{O}$ gestor escolar, ou autoridade competente, que recusar a matrícula de aluno com transtorno do espectro autista, ou qualquer outro tipo de deficiência, será punido com multa de 3 (três) a 20 (vinte) salários-mínimos” (BRASIL, 2012).

Desse modo, no campo enunciativo presente na análise da prova de redação, no enunciado referente ao discurso dos textos motivadores, em específico o "Texto II", os 
dados estatísticos permitem apresentar outros enunciados que corroboram o sentido de que o corpo com deficiência passou a ser tratado de diferentes formas por diferentes condições de produção, visto que se objetivou fomentar o discurso de que houve avanços nas políticas públicas para incluir os sujeitos Surdos nos espaços escolares, isto é inclusive reforçado com o saber jurídico.

É assim que as estratégias de governamentalidade, ao incidirem sobre a população, constroem o sentido de que o poder disciplinar está ganhando outras dimensões para a inclusão dos sujeitos Surdos, de fato, no espaço escolar por instituições públicas e privadas. Outro efeito de sentido produzido legitima o sujeito enunciador a colocar em destaque o olhar destinado ao corpo com deficiência e à produção de verdades diferentes entre os paradigmas existentes nas práticas educativas, ao que se reservou espaços e sentidos construídos em diferentes relações de podersaber. Desse modo, sempre existiram os termos "classes especiais " e "classes comuns", o que se modificou foram as condições de produção que promovem diferentes sentidos de inclusão do corpo com deficiência.

Passemos agora para a análise do discurso materializado no texto motivador denominado "Texto III" da prova de redação. O enunciado produz sentidos e vontades de verdade sobre o sujeito Surdo na relação do linguístico com o não linguístico. Há uma produção que objetiva falar da capacidade dos sujeitos em desenvolver atividades competentes com sua formação educacional, na ocupação de um cargo no mercado de trabalho. $\mathrm{O}$ enunciado do texto retoma uma campanha publicitária que integra uma rede de sentidos que promove uma atenção para o preconceito existente na inserção da inclusão do sujeito Surdo nas práticas sociais, especificamente, no mercado de trabalho. Esse efeito de sentido é reforçado com o enunciado: "E na sua empresa, tem espaço para mim?” (INEP, 2017, p. 19).

Esse discurso coloca em visibilidade o efeito de sentido de desrespeito à deficiência dos sujeitos Surdos, visto que a falta de valorização das habilidades é apresentada como um desafio a ser superado por todos, inclusive os donos de empresas. Esse sentido é construído na relação com o seguinte enunciado: "Trabalho não tolera preconceito. Valorize as diferenças" (INEP, 2017, p. 19); especificamente no uso da palavra "diferenças", retoma-se, através da memória discursiva, um atravessamento das práticas discursivas que enfocam a existência da discriminação social de outras épocas. 
$\mathrm{Na}$ análise do enunciado "Sou surdo e pós-graduado em marketing" (INEP, 2017, p. 19), destacado em letras maiúsculas e ocupando a parte mais superior da materialidade, percebe-se a produção de uma vontade de verdade em referência à educação como estratégia de inclusão dos sujeitos Surdos no mercado de trabalho. A construção desse efeito de sentido é reiterada com o enunciado não verbal, que apresenta um rosto na imagem de fundo preto, o qual ocupa um lugar central, e por um semblante de olhos fixos em um lugar distante.

Na cena enunciativa, o enunciado referente ao "Texto III" articula-se ao discurso da inclusão social do sujeito Surdo em uma interdiscursividade entre duas formações discursivas: a da educação e a do mercado de trabalho. Na historicidade que permeia o enunciado, o interdiscurso da inclusão social analisado com o enunciado "Sou surdo e pós-graduado em marketing" (INEP, 2017, p. 19) constrói um efeito de sentido que valoriza a formação dos sujeitos Surdos no espaço educacional e de trabalho, no entanto, promove um deslocamento de sentidos pela falta de oportunidade de inclusão no mercado de trabalho. As vontades de verdade que objetivam o sujeito Surdo na materialidade discursiva constroem os sentidos de competência e profissionalismo, já que o sujeito tem escolaridade e é pós-graduado em marketing. A campanha publicitária assegura o direito de falar sobre esses sujeitos.

No discurso analisado, o interdiscurso da inclusão social do sujeito Surdo se entrecruza na formação discursiva da esfera trabalhista com o enunciado "Trabalho não tolera preconceito" (INEP, 2017, p. 19), em que a produção discursiva se estabelece ativando uma memória discursiva que perpassa todo o discurso na presença de específicos dizeres. É a partir do que pode ser discursivizado sob específicos mecanismos de poder e saber da atualidade, que o discurso da inclusão social, no mercado de trabalho, pode acolher e valorizar as competências dos sujeitos Surdos adquiridas com a boa formação educacional.

No jogo das descontinuidades históricas e na construção das vontades de verdades que fizeram emergir esse enunciado "Texto III", da prova de redação do ENEM/2017, percebe-se uma discursividade sobre os desafios que os sujeitos Surdos enfrentam no Brasil. Por uma relação interdiscursiva é imperativo dizer que, entre o enunciado alusivo ao "Texto III" e o enunciado "Desafios para a formação educacional de surdos no Brasil" (INEP, 2017, p. 17), ocorre um entrecruzamento dos discursos, de 
modo que o espaço escolar e o de trabalho ainda são pouco ocupados por sujeitos Surdos, o que constrói o efeito de sentido de desafios a serem superados na sociedade.

Então é oportuno destacar que "todo enunciado é intrinsicamente suscetível de torna-se outro, diferente de si mesmo, se deslocar discursivamente de seu sentido para derivar para um outro" (PÊCHEUX, 2008, p. 53). O enunciado referente ao "Texto III", bem como os demais enunciados dos textos motivadores, mantêm relação com o tema da proposta de redação, o que contribui para o funcionamento da rede de sentidos das discursividades sobre o sujeito Surdo.

$\mathrm{Na}$ análise da prova de redação, no enunciado referente ao "Texto IV", é possível dizer que os discursos marcam as vontades de verdade que fazem parte das estratégias da governamentalidade, conforme disposto no discurso jurídico, através da "Lei $n^{\circ}$ 10.436". Na leitura discursiva do texto motivador, fomenta-se a divulgação do "Dia do Surdo", data de celebração das pessoas com deficiência auditiva, em âmbito nacional. Dessa forma, o sujeito enunciador apresenta a importância de se ter um dia destinado a comemoração dos avanços ao longo da história das práticas sociais e educacionais inclusivas. No exercício de um poder sobre a vida da população, como estratégias da biopolítica, articula-se discursivamente a inclusão do sujeito Surdo bem como a legalidade e o apoio do uso da Língua Brasileira de Sinais, conforme se pode perceber a seguir:

No Brasil, os surdos só começaram a ter acesso à educação durante o Império, no governo de Dom Pedro II, que criou a primeira escola de educação de meninos surdos, em 26 de setembro de 1857, na antiga capital do País, o Rio de Janeiro. Hoje, no lugar da escola funciona o Instituto Nacional de Educação de Surdos (INES). Por isso, a data foi escolhida como Dia do Surdo. Contudo, foi somente em 2002, por meio da sanção da Lei $n^{\circ}$ 10.436, que a Língua Brasileira de Sinais (Libras) foi reconhecida como segunda língua oficial do País. A legislação determinou também que devem ser garantidas, por parte do poder público em geral e empresas concessionárias de serviços públicos, formas institucionalizadas de apoiar o uso e difusão da Libras como meio de comunicação objetiva (INEP, 2017, p. 19).

O processo de construção de verdades e de fabricação de sentidos está atrelado à elaboração de estratégias discursivas que resgatam a historicidade vivida pelos sujeitos Surdos diante dos acontecimentos. Isso funde um retorno às práticas discursivas e não discursivas que inscreveram os diferentes sentidos para o corpo do sujeito Surdo e a 
educabilidade como estratégia de normalização desses sujeitos ao espaço escolar, no uso e na difusão da LIBRAS.

O enunciado retoma práticas sociais de exclusão no resgate da historicidade dos sujeitos Surdos com o retorno do acontecimento de 26 de setembro de 1857, o qual apresenta a instituição da primeira escola destinada ao atendimento e ao ensino desses sujeitos no Brasil. Data essa por meio da qual se celebram nacionalmente as conquistas das pessoas com deficiência auditiva. No discurso em análise, é construído um sentido de visibilidade da comunidade surda com o reconhecimento nacional por se comemorar a inclusão do sujeito Surdo e discutir suas necessidades.

$\mathrm{Na}$ atualidade, com o "Dia do Surdo", constrói-se um efeito de sentido de acolhimento desse sujeito e alerta para a deficiência na sociedade diante das novas relações de poder-saber. Ter uma data alusiva ao dia do sujeito Surdo retoma uma estratégia de governamentalidade semelhante às diferentes campanhas educativas que buscam sensibilizar para a causa em questão. Desse modo, as relações de poder-saber presentes em cada sociedade fazem legitimar determinadas práticas discursivas, sociais, vontades de verdades e efeitos de sentido em rede.

A prática de educabilidade do sujeito Surdo também sofreu seus efeitos. No enunciado “Contudo, foi somente em 2002, por meio da sanção da Lei n 10. 436, que a Língua Brasileira de Sinais (Libras) foi reconhecida como segunda língua oficial no País" (INEP, 2017, p. 19), percebe-se o efeito de sentido que se constrói com o saber jurídico através da sanção da lei como uma estratégia de fomento à educação do sujeito Surdo em seguir as normas, por ter a LIBRAS oficializada com o poder governamental.

No discurso apresentado como texto motivador "Texto IV", em análise, percebese a construção do efeito de apoio por todas as estruturas sociais em aderirem a essa forma de comunicação. Para tanto, há um destaque para a necessidade social de conhecer a LIBRAS. Com as análises dos enunciados, textos motivadores, que constituem a prova de redação, há ainda nessa produção discursiva um outro enunciado que se localiza na parte inferior da prova de redação, o qual se apresenta após os enunciados dos textos motivadores. Trata-se do enunciado que se refere à "Proposta de redação", que, em conjunto com os outros enunciados já analisados, está em rede e forma o campo discursivo da prova de redação do ENEM/2017. 
Portanto, não existe "enunciado livre, neutro ou independente; mas sempre um enunciado fazendo parte de uma série ou de um conjunto, desempenhando um papel no meio dos outros, neles se apoiando e deles se distinguindo" (FOUCAULT, 2009, p. 112). Analisando a prova de redação do ENEM, o enunciado que aparece após os textos motivadores intitula-se "Proposta de redação" e apresenta a temática destacada em negrito, disciplinando os candidatos, como é reproduzido a seguir:

\begin{abstract}
A partir da leitura dos textos motivadores e com base nos conhecimentos construídos ao longo de sua formação, redija texto dissertativo-argumentativo em modalidade escrita formal da língua portuguesa sobre o tema "Desafios para a formação educacional de surdos no Brasil", apresentando proposta de intervenção que respeite os direitos humanos. Selecione, organize e relacione, de forma coerente e coesa, argumentos e fatos para a defesa de seu ponto de vista (INEP, 2017, p. 19).
\end{abstract}

É possível percebermos a produção de uma vontade de verdade inscrita na ordem do que é dito e dos não ditos, na presença legitimada de um sujeito enunciador específico que disciplina as condutas dos candidatos. A relação que esse enunciado mantém com os textos motivadores se dá na presença de diferentes campos associados com os outros enunciados já analisados, apresentados na prova de redação do ENEM.

Nesse sentido, por uma oportuna relação interdiscursiva dos enunciados, "não há nenhum que não tenha, em torno de si, um campo de coexistências, efeitos de série e de sucessão, uma distribuição de funções e papéis" (FOUCAULT, 2009, p. 112). Logo, percebe-se um efeito de sentido de auxílio para os participantes do exame. Funciona um poder disciplinar sob a escrita dos candidatos através de um discurso normatizador, o qual destaca uma norma legitimada socialmente. O uso das palavras "selecione", "organize" e "relacione" reforça o sentido de assistência, de que precisam selecionar argumentos, organizá-los e refletir sobre o tema na atualidade.

Além disso, com a presença do enunciado "Desafios para a formação educacional dos surdos no Brasil” (INEP, 2017, p. 19), ligado a outros discursos, tornase possível dizer que, por muito tempo, os sujeitos Surdos sofreram por fugirem do padrão de normalidade. As práticas de exclusão aplicadas a esse corpo caracterizaram períodos de exercício do poder soberano sobre esses sujeitos. O sentido de desafios já passou a ser considerado em relação ao padrão de normalidade dos indivíduos aptos a 
viverem na sociedade, o que na contemporaneidade esse sentido recebe outros tratamentos.

É assim que percebemos a construção dos sentidos no uso da palavra "Desafios" no tema da proposta de redação do ENEM em 2017, através de um resgate de memória discursiva constrói-se uma interdição com tudo o que já foi dito sobre os sujeitos Surdos. Com efeito, na ordem do discurso da inclusão social e das estratégias da governamentalidade por novas relações de poder-saber, têm-se outros sentidos para o uso da palavra "Desafios". O princípio de raridade do enunciado é específico de sua emergência, fazendo com que as vontades de verdade sejam atravessadas em diferentes práticas discursivas na história.

Pode-se, assim, analisando o enunciado referente à "Proposta de redação", perceber o efeito de sentido de inclusão no seguinte dizer: “[...] apresentando proposta de intervenção que respeite os direitos humanos" (INEP, 2017, p. 19), em que se resgata uma memória discursiva no uso da palavra "respeite", promovendo o efeito de igualdade. Há a presença de uma biopolítica no discurso de respeito mútuo a todos com ou sem deficiência, objetivando sanar as "barreiras" e os "desafios" ainda existentes aos sujeitos Surdos na sociedade. É importante ressaltar que isso não é específico deste tema, pois todas as propostas têm esse mesmo sentido de valorização dos direitos humanos, mas que não deixa de ser uma convocação biopolítica.

Ainda na leitura discursiva desse enunciado, articula-se o discurso da inclusão social do sujeito Surdo em uma interdiscursividade entre as formações discursivas da educação e a do respeito aos direitos humanos. Ocorre uma correlação entre os enunciados através do sujeito que enuncia, no exercício da função enunciativa, que os sujeitos Surdos precisam de respeito diante das necessidades para que os desafios sejam superados. A prova de redação do ENEM/2017, ao se enquadrar no campo das políticas sociais, surge como uma estratégia biopolítica que atua na promoção do governo das populações.

Os enunciados da prova de redação do ENEM/2017 se inscrevem em suas próprias formulações, o que garante seu funcionamento no tocante a disciplinar os candidatos por um efeito disciplinar às normas e diretrizes na escrita da redação, bem como disciplinar a população por um efeito do poder sobre o corpo social. As estratégias de normalização dos sujeitos Surdos ocorrem através dos mecanismos de 
educabilidade à população, assim, percebemos a construção dos efeitos de sentido no exercício de um poder normatizador aos candidatos e por um poder normalizador aos sujeitos Surdos.

\section{Considerações finais}

É através dessa relação entre os campos jurídico, pedagógico e médico que a formação discursiva do ENEM se caracteriza como uma instância de delimitação do objeto de que fala. Assim, retomando-se o tema da prova com o enunciado "Desafios para a formação educacional de surdos no Brasil”" (INEP, 2017, p. 19) e no uso da palavra "Desafios", é possível dizer que o efeito de sentido de desafio no âmbito educacional para os sujeitos Surdos se dá por toda a história de exclusão social. Já ao sujeito candidato, o efeito de sentido de desafio remete ao aparecimento inesperado do tema, em que é disciplinado a produzir um texto sobre um assunto que é pouco discutido nas escolas. Em suma, devemos "primar pela desconstrução das evidências opressoras, que se produzem tanto em afirmações de sua continuidade quanto em declarações de sua ruptura em relação a outras práticas do passado e do presente" (PIOVEZANI, 2016, p. 93). É assim que o governo atua através do exame, ao dar visibilidade aos sujeitos Surdos, os quais foram duramente segregados e silenciados na história, excluídos de sua própria cidadania. 


\section{REFERÊNCIAS}

BRASIL. Lei $\mathbf{n}^{\mathbf{0}}$ 10.436. Brasília, 2002. Disponível em: <http://www.planalto.gov.br/ccivil_03/leis/2002/110436.htm>.Acesso em: 20 abr. 2019. BRASIL. Presidência da República. Lei no 12. 764, de 27 de dezembro de 2012. Disponível em: <http://www.planalto.gov.br/ccivil_03/_ato20112014/2012/lei//12764.htm>. Acesso em 8 de nov. 2017.

INEP. Ministério da Educação. Prova do Exame Nacional do Ensino Médio/2017. Prova Amarela $2^{\circ}$ dia. Disponível em: <http://portal.inep.gov.br/web/guest/provas-egabaritos>. Acesso em 10 de set. 2018 .

FERNANDES, C. A. Discurso e sujeito em Michel Foucault. São Paulo: Intermeios, 2012.

FOUCAULT, M. Em defesa da sociedade. Curso no College de France (1975 - 1976). São Paulo: Martins Fontes, 2005.

FOUCAULT, M. A arqueologia do saber. Rio de Janeiro: Forence Universitária, 2009. FOUCAULT, M. A ordem do discurso. São Paulo: Edições Loyola, 2013.

FOUCAUlT, M. Vigiar e Punir: nascimento da prisão. Trad. Raquel Ramalhete. Petrópolis, RJ: Vozes, 2014.

FOUCAULT, M. Microfísica do poder. Trad. Roberto M. Rio de Janeiro: Paz e Terra, 2015.

PÊCHEUX, M. O discurso: estrutura ou acontecimento. Campinas, SP: Pontes Editores, 2008.

PIOVEZANI, C. Instantâneos de duradouros estigmas: consensos sobre as vozes popular e feminina (da Retórica antiga à mídia contemporânea). In:. CURCINO, L; PIOVEVANI, C; SARGENTINI, V. (Orgs). (In)Subordinações contemporâneas: consensos e resistências nos discursos. São Carlos: EdUFScar, 2016, p. 73-99. 